\title{
UN MARCO ORIENTADOR PARA ASEGURAR LA PROTECCIÓN INTEGRAL Y CONTINUIDAD DEL APRENDIZAJE DE CALIDAD DE NIÑAS, NIÑOS Y JÓVENES EN CONTEXTOS DE EMERGENCIA: UNA MIRADA DESDE LATINOAMÉRICA ANTE LA PANDEMIA COVID-19
}

\author{
HOSY OROZCO
}

RESUMEN: Son cuatro los principales actores educativos que deben proteger y cuidar de las niñas, niños y jóvenes en contextos de emergencia como ha sucedido en la pandemia COVID-19, y garantizar la continuidad de su formación de calidad: las autoridades gubernamentales y especialmente los ministerios o secretarías de educación, directivos de centros educativos, el equipo de educadores de cada centro educativo y los familiares de los estudiantes. A partir de una amplia revisión bibliográfica y de la experiencia tenida en esta emergencia en países latinoamericanos, particularmente en el caso de Guatemala, se hace una propuesta de un marco orientador que establece las relaciones de los principales actores involucrados en el proceso formativo, y plantea en el marco de esas relaciones las principales acciones que deben promoverse para preservar la continuidad de un aprendizaje integral y de calidad, en contextos de futuras emergencia. Para asegurar la calidad formativa se plantea, además de innovar los métodos de aprendizaje, atender los aspectos emocionales del aprendizaje, los aprendizajes no pretendidos y la evaluación entendida como retroalimentación.

Palabras Clave: Covid-19; política educativa; pandemia; educación; educación a distancia, Pedro Morales; educación en crisis, educación postcovid.

A guiding framework to ensure the comprehensive protection and continuity of quality learning of girls and boys in emergency contexts: a view from Latin America during the COVID-19 pandemic

ABSTRACT: There are four main educational actors who must protect and care for girls, boys and young people in emergency contexts such as the COVID-19

1 Universidad Rafael Landívar (Guatemala). Correo electrónico: horozco@url.edu.gt. 
pandemic, and guarantee the continuity of their quality training: government authorities and especially ministries o secretariats of education, directors of educational centers, the team of educators of each educational center and the families of the students. Based on an extensive bibliographic review and the experience of this emergency in Latin American countries, particularly in the case of Guatemala, a proposal is made for a guiding framework that establishes the relationships of the main actors involved in the training process. Within the framework of these relationships, the author proposes the main actions that should be promoted to preserve the continuity of comprehensive and quality learning, in future emergency contexts. In order to ensure the quality of training, in addition to innovative learning methods, it is proposed to address the emotional aspects of learning, unintended learning and evaluation understood as feedback.

KEY WORDS: COVID-19; educational policy; pandemic; education; distance education, Pedro Morales; education in crisis, postcovid education.

\section{INTRODUCCIÓN}

La pandemia COVID-19 ha representado retos para todas las actividades humanas en el mundo, y la educación fue de las más afectadas por la suspensión de actividades presenciales, especialmente en países en desarrollo con alto nivel de pobreza como Guatemala, donde antes de la pandemia ya existían enormes rezagos e inequidades educativas, que limitan las posibilidades de una adecuada continuidad de formación a distancia.

A partir de una amplia revisión bibliográfica y de la experiencia tenida en esta emergencia en países latinoamericanos, particularmente en el caso de Guatemala, se hace una propuesta de un marco orientador (Cuadro 1) que establece las relaciones de los principales actores involucrados en el proceso formativo, los ministerios o secretarías de educación, los directivos de centros educativos, el equipo de educadores y los familiares de los estudiantes, planteando en el marco de esas relaciones unas acciones prioritarias que deben promoverse para preservar la continuidad de un aprendizaje integral y de calidad en esta pandemia, y en futuras emergencias sanitarias, climáticas $\mathrm{y}$ sociales. 
CuAdro 1. Relaciones y acciones DE PRINCIPALES ACtORES EDUCATIVOS PARA ASEGURAR LA CONTINUIDAD DE UNA FORMACIÓN INTEGRAL Y DE CALIDAD EN CONTEXTOS DE EMERGENCIA

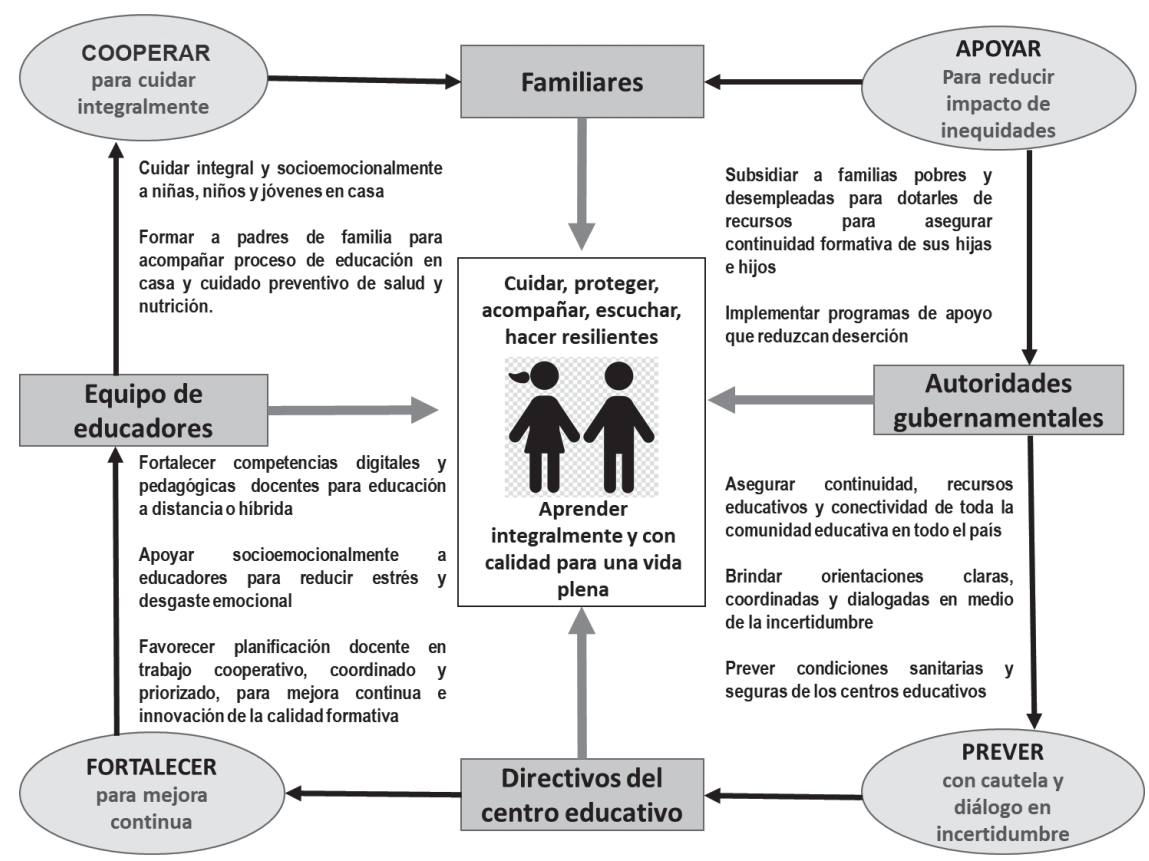

Fuente: elaboración propia.

\section{CLAVES PARA ASEGURAR EL CUIDADO INTEGRAL Y CONTINUIDAD DEL APRENDIZAJE DE CALIDAD EN CONTEXTOS DE EMERGENCIA}

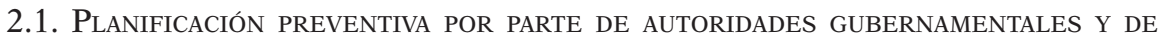 CENTRO}

Con la pandemia COVID-19, las autoridades gubernamentales educativas se vieron desbordadas, con incertidumbre ante las disposiciones sanitarias y posturas encontradas sobre el retorno a clases presenciales, y en países en desarrollo con limitados recursos y contextos sociales difíciles para asegurar la continuidad de la formación en modalidad a distancia y de calidad, especialmente en el sector educativo público. 


\subsubsection{Asegurar la continuidad, previendo los recursos educativos y conectividad de toda la comunidad educativa en todo el país}

La mayoría de países latinoamericanos suspendieron actividades educativas presenciales entre el 14 y 22 de marzo, y cada país y centro educativo abordó de manera diferente y con diversa efectividad el reinicio de clases a distancia, según sus posibilidades. Los países que pudieron adaptarse de mejor manera a esta modalidad fueron los que contaban con alto porcentaje de población estudiantil con conectividad de internet, o que históricamente tenían desarrollados programas de formación a distancia por medios alternos como radio y televisión.

En el primer caso destaca el caso de Uruguay. Emanuela Di Gropello, Gerente del área de educación del Banco Mundial para Latinoamérica y el Caribe, que dio seguimiento a cómo los países utilizaban la tecnología para dar apoyo al aprendizaje remoto durante la pandemia, señala que Uruguay estaba bien preparado porque «dedicó muchos años a garantizar la conectividad y el acceso a herramientas digitales para la comunidad educativa» (Pais, 2020), gracias al Plan Ceibal generalizó la entrega de una laptop a cada alumno de las escuelas públicas, disminuyendo la brecha de acceso a la computadora entre sectores sociales de más bajos ingresos. Al momento de reiniciar actividades a distancia casi todos los centros educativos contaban con red wifi, y el $98 \%$ de los alumnos matriculados en junio de 2020 contaban con acceso a internet de banda ancha.

En el segundo caso destaca México, que reinició su educación a distancia aprovechando su modalidad formativa conocida como Telesecundaria, un programa estatal creado en 1968 para ofrecer educación secundaria en áreas rurales a través de la televisión, y en el que se ha invertido equipo humano y técnico para desarrollar programas educativos a nivel nacional y en diversos grados. En este caso, se realizaron alianzas con televisoras del país para masificar y ampliar esta modalidad de estudio a otros niveles educativos.

Pero no pocos países en desarrollo enfrentaron este reinicio con mayor dificultad, por no contar con estas condiciones óptimas de conectividad. Este es el caso de Guatemala, donde en 2016 apenas el $11 \%$ de escuelas públicas del país tenían acceso a alguna tecnología de información y comunicación. Según el más reciente censo poblacional y de características generales de hogares realizado en 2018 (Instituto Nacional de Estadística, 2018), de un total de 3,275,931 hogares en todo el país, solo el $17.26 \%$ de hogares tienen acceso a internet; $21.26 \%$ tiene acceso a una computadora; $65.34 \%$ tiene acceso a radio; y $70.51 \%$ a televisión. Esta situación obligó al Ministerio de Educación a implementar su Programa «Aprendo en casa» en diversas modalidades de formación a distancia, usando televisión, radio, plataforma 
web, y guías y materiales de aprendizaje impresos, con el riesgo de no poder concentrarse en fortalecer una modalidad prioritaria.

Cuadro 2. Estrategia de multimedios para el Reinicio de Clases EN GUATEMALA, EN FUNCIÓN DEL TIPO DE MEDIO DISPONIBLE POR LAS FAMILIAS

\begin{tabular}{|c|c|c|c|c|}
\hline $\begin{array}{l}\text { Tecnologías de } \\
\text { información y } \\
\text { comunicación } \\
\text { disponibles en } \\
\quad \text { hogares }\end{array}$ & $\begin{array}{l}\text { Total de ho- } \\
\text { gares a nivel } \\
\text { nacional } \\
\text { (Censo 2018) }\end{array}$ & $\begin{array}{l}\text { Número } \\
\text { de } \\
\text { hogares } \\
\text { con } \\
\text { acceso }\end{array}$ & $\begin{array}{c}\text { Porcentaje } \\
\text { de } \\
\text { familias } \\
\text { con } \\
\text { acceso }\end{array}$ & $\begin{array}{c}\text { Recursos del } \\
\text { Programa } \\
\text { «Aprendo en casa», } \\
\text { implementados } \\
\text { por Mineduc }\end{array}$ \\
\hline & $3,275,931$ & & & \\
\hline Radio & & $2,140,443$ & 65.34 & $\begin{array}{l}\text { Programas-clases } \\
\text { radiales }\end{array}$ \\
\hline Televisión & & $2,309,915$ & 70.51 & \multirow{2}{*}{$\begin{array}{l}\text { Programas-clases por } \\
\text { televisión abierta }\end{array}$} \\
\hline Cable & & $1,786,566$ & 54.54 & \\
\hline Computadora & & 696,618 & 21.26 & \multirow{2}{*}{$\begin{array}{l}\text { Guías y recursos en } \\
\text { Plataforma online } \\
\text { Mineduc digital }\end{array}$} \\
\hline Internet & & 565,270 & 17.26 & \\
\hline $\begin{array}{l}\text { Periódicos im- } \\
\text { presos }\end{array}$ & & s.d. & s.d. & $\begin{array}{l}\text { Guías impresas de } \\
\text { aprendizaje }\end{array}$ \\
\hline
\end{tabular}

Fuente: elaboración propia con datos del Censo poblacional (INE 2018), e informativos del MINEDUC de Guatemala.

Este es un enorme reto para el país, considerando que en 2019 el sistema educativo tenía 4,176,977 estudiantes inscritos desde preprimaria hasta secundaria, en sector público y privado, de los cuales 2,047,329 eran estudiantes de nivel primario y del sector público, en su mayoría ubicados en departamentos y regiones con bajo acceso a conectividad de internet y electricidad. A modo de ejemplo, en los departamentos de Alta Verapaz, Huehuetenango y San Marcos se encuentra la mayor cantidad de hogares del país y alumnos matriculados en primaria, y es donde los hogares tienen los más bajos niveles de acceso a internet (solo el 5.76 a $8.32 \%$ de la población). Si bien el acceso a celulares inteligentes está más generalizado (entre el 41.00 y $57.37 \%$ ), para poder seguir estudios a distancia en modalidad virtual deben realizar gastos altos en uso de datos móviles.

También la educación superior se vio afectada por esta situación en Guatemala, la Vicerrectoría Académica y el Departamento de Planificación y Seguimiento de la Universidad Rafael Landívar (URL 2020) realizaron una 
encuesta entre sus estudiantes, a dos semanas de iniciadas las clases en modalidad a distancia, donde se les preguntaba su disponibilidad de internet por computadoras u otros dispositivos para seguir clases en modalidad virtual. Estudiantes de campus con alto porcentaje de estudiantes proveniente de zonas rurales, manifestaron tener dificultades de conectividad por falta de acceso a internet residencial: $45.01 \%$ en Campus de Quiché y $33.18 \%$ en Campus de La Verapaz. El problema no solamente es la falta de acceso a internet residencial, sino la mala calidad de la conectividad en sus lugares de residencia que les dificulta seguir clases por videoconferencia sincrónica. $68.73 \%$ de los estudiantes de Quiché manifestaron tener dificultades por insuficiente acceso a internet donde se encuentran, y varios refieren que el costo por acceder a través de datos móviles eleva sus costos de estudios.

Por esa razón, desde inicios de 2021 se viene discutiendo una iniciativa legislativa para dar acceso gratuito a internet con fines educativos, y varios gobiernos de países en desarrollo negocian con proveedores locales, para facilitar y bajar el costo del acceso a materiales educativos en móviles o celulares. En esta línea, el Fondo de las Naciones Unidas para la Infancia (UNICEF) señala que «las desigualdades inherentes en el acceso a las herramientas y a la tecnología podrían agravar la crisis mundial del aprendizaje» (UNICEF, 2020 b), y exhorta a los gobiernos a «ampliar el acceso a internet para cada escuela y para cada niño», considerando que en 71 países del mundo menos de la mitad de la población tiene acceso a internet, y en países pobres menos de una cuarta parte de la población cuenta con internet, y dos tercios del total de estudiantes de entre 3 y 17 años en el mundo no tienen conexión a Internet en sus hogares. La Unión Internacional de Telecomunicaciones y UNICEF advierten la necesidad de realizar «inversiones urgentes para reducir la brecha digital, que impide actualmente a los niños y los jóvenes acceder a un aprendizaje digital de calidad y a oportunidades en línea»(UNICEF, 2021).

Cerrar la brecha digital es urgente en estos países, porque las tecnologías digitales se han convertido en algo vital en esta crisis (Grupo Banco Mundial, 2020), y lo serán en futuras crisis.

\subsubsection{Prever y brindar orientaciones claras y coordinadas en medio de la incertidumbre}

Esta pandemia recordó la importancia de la previsión educativa, lo que requiere un riguroso diagnóstico preventivo usando datos del pasado, presente y posibles tendencias del futuro, para disponer y anticipar lo conveniente para atender a contingencias (RAE) de la mejor manera posible. Esto 
supone preguntarse ¿Qué puede hacerse con mayor certeza y probabilidad, en medio de la incertidumbre?

Pareciera que la pandemia del COVID-19 tomó a los sistemas educativos por sorpresa, y no preparados para enfrentar la suspensión de actividades educativas presenciales. De este virus se tuvo primeras noticias el $31 \mathrm{de}$ diciembre de 2019 en Wuhan, provincia de Hubei, China, donde crecieron los casos de neumonía. La mayoría de países fueron suspendiendo actividades educativas presenciales entre el 13 y 22 de marzo de 2020, luego que el 9 de marzo la Organización Mundial de la Salud (OMS) recomendara cerrar centros educativos a los países donde se venía agudizando la transmisión comunitaria de coronavirus, y que el 11 de marzo comunicara que COVID-19 se declaraba una pandemia. Los organismos internacionales ya estaban advertidos días antes y se venían preparando, como lo evidencia que la OMS, UNICEF y la Federación Internacional de Sociedades de la Cruz Roja y de la Media Luna Roja (IFRC) divulgan el 10 de marzo una «Guía provisional para la prevención y control de la COVID-19 en las escuelas» (UNESCO, UNICEF, BM, PMA, 2020).

Si bien los gobiernos y sistemas educativos no previeron, importantes voces advirtieron con mucha antelación la alta posibilidad de darse una pandemia global. BBC Mundo recogía el 1 de enero de 2017 una entrevista que hizo a Bill Gates, donde advertía que «el mundo es vulnerable a una gran epidemia» (Redacción BBC, 2017), en mayo de 2018 Bill Gates solicita a las autoridades gubernamentales de EEUU liderar la lucha contra una pandemia que podría matar a 33 millones de personas (INFOBAE, 2018), y el 18 de septiembre de 2019 la BBC recoge la alerta de funcionarios de la OMS que señalaban «la amenaza real de una pandemia fulminante» e inminente (Redacción BBC, 2020).

Además, una situación parecida ya se había vivido en 2014 en países de África, con la expansión del virus del Ébola con alta tasa de mortalidad y que también se transmite de especies animales hasta llegar a humanos. En marzo de 2014 Guinea, Liberia y Sierra Leona cerraron más de 10,00 escuelas entre 6 y 8 meses, afectando a casi cinco millones de estudiantes, y solo pudieron abrir en 2015. Esta situación muy parecida a la que ahora vivimos, ha sido documentada ampliamente por la Fundación Malala, en su informe Girls education and Covid-19, What past shocks can teach us about mitigating the impact of pandemics (Malala Fund, 2020).

Por ello el surgimiento de grandes pandemias no debe sernos algo desconocido, la historia humana y de algunas regiones del mundo ha estado y estará acompañada de pandemias de alta letalidad (INFOBAE, 2020), y los sistemas educativos deben estar preparados para pandemias y emergencias 
futuras. Por esta razón, el Equipo del Informe GEM-UNESCO en su Blog de la Educación Mundial, recordaba que en un año existe el $1 \%$ de probabilidad de una pandemia de gripe (de 6 millones de muertes), y en 30 años el $25 \%$ de probabilidad, por lo que advierten que «las pandemias deben tenerse en cuenta en la planificación de la educación» y «el cierre de escuelas durante los brotes de enfermedades no debe tomarse a la ligera» (Informe GEM, 2020), como tampoco su reapertura.

UNICEF, UNESCO, el Programa Mundial de Alimentos (PMA), el Banco Mundial, la Federación Internacional de la Cruz Roja (FICR) y el Alto Comisionado de las Naciones Unidas para los Refugiados (ACNUR), han elaborado varias orientaciones intersectoriales para atender la educación durante las pandemias y para la reapertura segura de las escuelas. En una de sus primeros documentos orientadores ofrecía un primer «Marco para la reapertura de las escuelas»(UNESCO, UNICEF, BM, PMA, 2020). Este importante documento proponía que una vez se determinara qué escuelas se reabrirían, deberían utilizarse seis dimensiones claves para evaluar su preparación y orientar la planificación: operaciones seguras, atención especial al aprendizaje, atención a los niños más marginados, y asegurar el bienestar y protección, y para hacer viables estas cuatro dimensiones se deben considerar el diseño de adecuadas políticas y la financiación.

CUAdRo 3. DimENSIONES ClaVE PARA LA REAPERTURA DE LAS ESCUELAS, PROPUESTAS POR UNICEF, UNESCO, BANCO MUNDIAL Y PROGRAMA MUNDIAL DE ALIMENTOS

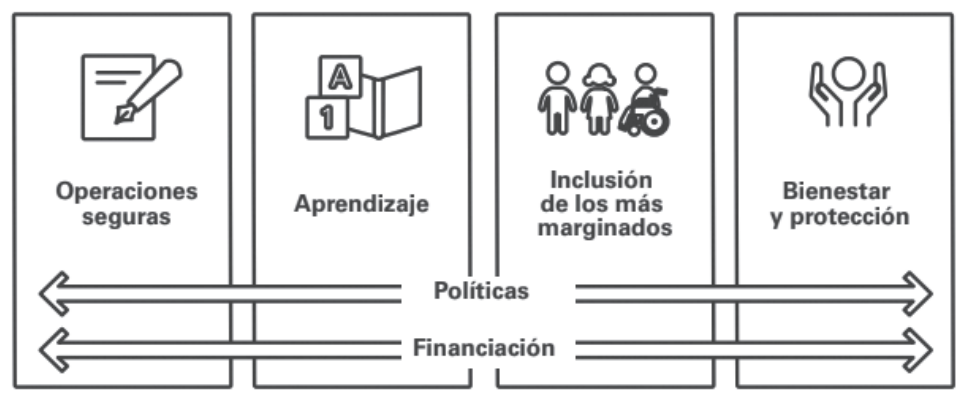

Fuente: UNICEF 2020 a.

Este proceso de análisis y planificación debe ser una prioridad para los gobiernos y llevarse a cabo tan pronto como sea seguro (UNICEF, 2020 a), considerando el contexto y condiciones locales de cada país y regiones, especialmente en zonas de alta densidad poblacional y con carencias de servicios 
públicos como el agua potable, para garantizar la mejora de las condiciones de operación, el logro de aprendizajes de calidad, asegurar la equidad en el acceso a la educación, y fortalecer la protección, salud y seguridad de estudiantes y educadores. Concretamente propone prepararse con políticas, procedimientos y planes de financiación para el mejoramiento de la enseñanza y las operaciones seguras; en el aprendizaje recomienda fortalecer las prácticas de aprendizaje a distancia, en la reapertura «adaptar la educación a distancia a una modalidad combinada de enseñanza y aprendizaje»; en la inclusión, durante la reapertura «adoptar métodos proactivos para reintegrar a los niños marginados y a los que no asisten a la escuela», y estrategias de recuperación escolar "para compensar el tiempo de instrucción perdido»; en el bienestar y protección «invertir en agua, saneamiento e higiene a fin de mitigar los riesgos», y "vigilar activamente los indicadores de salud» (UNESCO, UNICEF, BM, PMA, 2020).

Preparar y garantizar espacios dignos, saludables y seguros en el retorno a las escuelas, es tarea vital para los gobiernos y directivos de centros educativos, donde ocupa un lugar prioritario los servicios de agua y saneamiento. Según datos del Programa conjunto de Monitoreo de OMS/UNICEF, en 2019 un $43 \%$ de las escuelas de todo el mundo no tenían acceso básico al lavado de manos con agua y jabón. En Guatemala, en septiembre de 2020 el Ministerio de educación confirmaba que 10 mil escuelas del país no tenían agua, ni sanitarios, y solicitaban aumento presupuestal en 2021 para remozar al menos mil de ellas (García, 2020). También pueden verse otras recomendaciones de UNICEF (2020a) en su informe «Educación en pausa», donde plantea que la planificación debe considerar la evidencia epidemiológica, factores socioeconómicos y de salud pública, un análisis cuidadoso de los beneficios y riegos para el aprendizaje; planificar con un enfoque intersectorial que también aborde otros riesgos que enfrentan los niños, niñas y adolescentes cuando no están en la escuela (violencia familiar, abandono escolar, entre otras); y con una visión de largo plazo para aprender de las lecciones aprendidas durante esta suspensión, para tener centros educativos mejor preparados y resilientes para próximas emergencias o crisis.

\subsection{Apoyo integral a docentes por parte DE AUtOridades DEL CEnTRo EDUCATIVO}

Los directivos de los centros educativos se han convertido en actores clave para la adecuada y previsora planificación de las actividades administrativas y formativas, durante y después de la pandemia, y su rol es vital y estratégico 
para acompañar y orientar a la comunidad educativa en momentos de crisis. UNICEF Argentina elaboró una serie de cartillas, denominada «Los equipos de conducción frente al COVID-19: claves para acompañar a los docentes, las familias y los estudiantes en contextos de emergencia», que abordan desafíos específicos que afrontan los equipos de conducción en el marco de la emergencia: 1) la planificación en contextos de emergencias; 2) El acompañamiento al equipo docente, las familias y estudiantes; 3) la contención emocional del equipo docente y de las familias; 4) la retroalimentación de las actividades escolares; 5) el desarrollo de nuevas prácticas de enseñanza, y 6) el regreso a las clases presenciales (Castro, 2020).

En lo educativo, los directivos deben acompañar, animar y orientar al equipo de profesores para enfrentar de mejor manera el proceso formativo en este contexto de emergencia, donde ocupan un lugar especial el fortalecer sus competencias tecnológicas y pedagógicas para contextos a distancia o híbridos, brindarles apoyo socioemocional para reducir su estrés y desgaste emocional, favorecer el trabajo cooperativo y coordinado entre docentes para apoyarse mutuamente, no sobrecargar a los estudiantes, y mejorar de manera permanente el proceso de aprendizaje remoto o híbrido que favorezca la motivación hacia el aprendizaje.

\subsubsection{Fortalecer las competencias digitales para contextos a distancia o híbridos,} a partir de un marco gradual de desarrollo

La pandemia de COVID-19 vino a confirmar y acelerar la necesidad de formar en todos los educadores las competencias digitales para un adecuado uso educativo de nuevas tecnologías de información y comunicación -TIC(dispositivos electrónicos inteligentes, las computadoras y la hiperconectividad), porque al momento de migrar la formación al modelo virtual no estaban suficientemente preparados. Diversas investigaciones realizadas entre profesores de distintos niveles educativos, en varios países como Chile (Fundación Chile-Circular HR, 2020), Argentina (Duro et al. 2020), Guatemala (Alvarado, H. 2020), evidencian que la mayoría de docentes no se sienten bien preparados para el uso adecuado de las tecnologías para ambientes educativos a distancia.

El estudio de la Fundación Chile y Circular HR (Fundación Chile-Circular HR, 2020), realizada en julio de 2020 a una muestra de 2.657 docentes chilenos de primaria y secundaria, reveló que una de las causas de estrés y agotamiento docente era la tensión que para docentes -especialmente de mayor edad- representaba el enfrentarse al uso intensivo y demandante de las nuevas tecnologías. La mayoría $(65.5 \%$ de la muestra) percibía que no habían recibido suficientes capacitaciones para uso de las TIC, o que las 
capacitaciones existentes no les formaron para desarrollar mejores procesos educativos a distancia, y no se les había provisto de recursos para su trabajo formativo de forma remota. El estudio identificó que entre mayor capacitado se sentía el educador, su estrés disminuía, no así su agotamiento al tener que preparar nuevos y diversos materiales digitales sobre la marcha.

Otro estudio de Duro et al. (2020), realizado entre docentes argentinos, identificó que la percepción respecto a su débil preparación en competencias digitales se incrementaba a medida que aumentan los niveles educativos en los que se desempeñan, además que Whatsapp se convirtió en el principal canal de comunicación entre educadores y alumnos en todos los niveles educativos, algo confirmado por múltiples estudios, y que obliga a profundizar en su uso educativo adecuado. El estudio de Alvarado (2020) en Guatemala realizado en una muestra de 137 estudiantes y 17 docentes de una facultad de la Universidad de San Carlos de Guatemala, identificó que también la mayoría de estudiantes consideran no tener la capacitación y actualización en el uso eficiente de las herramientas tecnológicas para un adecuado proceso de aprendizaje remoto.

La formación de educadores en estas competencias digitales, con énfasis en su uso pedagógico, además de su alfabetización digital (habilidades para la gestión de las TIC), la alfabetización informacional (gestionar la información de forma segura, creativa y responsable) y el gobierno institucional de las TIC (su desarrollo gradual en la institución), se hace fundamental para mejorar la calidad de la formación recibida en modalidad virtual o híbrida. CEPAL y UNESCO afirman que en Latinoamérica esta pandemia ha puesto en evidencia la brecha digital de estudiantes y docentes, lo que repercute en la calidad educativa (CEPAL-UNESCO, 2020).

Díaz y Loyola (2021), haciendo una revisión de diversos estudios en esta pandemia, concluyen que esta crisis ofrece una valiosa oportunidad para repensar la educación que ofrecemos, incorporando de manera progresiva, permanente y adecuada esas nuevas tecnologías que permitan avanzar hacia ese ideal de sociedad de la información, la comunicación y el conocimiento, donde la formación docente es vital. Para orientar esta formación, es importante contar con algún marco referencial como el Marco Europeo para la Competencia Digital de los Educadores, dirigido a docentes de todas las etapas del sistema educativo y que plantea 22 competencias digitales organizadas en seis áreas de desarrollo. Como no todos los educadores están al mismo nivel, estas competencias deben ser desarrolladas de acuerdo a los niveles de competencia utilizados por el Marco común europeo de referencia para las Lenguas (CEFR), que van desde A1 (novato), A2 (exploradores), B1 (integradores), B2 (expertos), C1 (líderes), hasta C2 (pioneros). 
Cuadro 4. Marco europeo para la competenca digital de los educadores

\begin{tabular}{|c|c|c|c|}
\hline \multirow{2}{*}{$\begin{array}{l}\text { 1. Compromiso } \\
\text { profesional }\end{array}$} & 2. Recursos Digitales & \multirow{3}{*}{$\begin{array}{l}\text { 5. Empoderar a los } \\
\text { Estudiantes }\end{array}$} & \multirow{2}{*}{$\begin{array}{c}\text { 6. Facilitar la } \\
\text { Competencia Digital } \\
\text { de los Estudiantes }\end{array}$} \\
\hline & 2.1 Selección de recursos digitales & & \\
\hline \multirow{2}{*}{ 1.1 Gestión de datos } & 2.2 Organizar, compartir y publicar & & \multirow{2}{*}{$\begin{array}{l}6.1 \text { Información y } \\
\text { alfabetización } \\
\text { mediática }\end{array}$} \\
\hline & 2.3 Creación y modificación & \multirow{3}{*}{$\begin{array}{l}5.1 \text { Accesibilidad e } \\
\text { inclusión }\end{array}$} & \\
\hline \multirow{2}{*}{$\begin{array}{l}1.2 \text { Comunicación de la } \\
\text { organización }\end{array}$} & 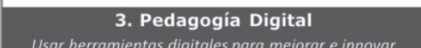 & & \multirow{2}{*}{$\begin{array}{l}6.2 \text { Comunicación y } \\
\text { colaboración digital }\end{array}$} \\
\hline & 3.1 Instrucción & & \\
\hline \multirow{3}{*}{$\begin{array}{l}1.3 \text { Colaboración } \\
\text { profesional }\end{array}$} & 3.2 Interacción profesor-alumno & \multirow{4}{*}{$\begin{array}{l}5.2 \text { Diferenciación y } \\
\text { personalización }\end{array}$} & \multirow{3}{*}{$\begin{array}{l}6.3 \text { Creación de } \\
\text { contenido digital }\end{array}$} \\
\hline & 3.3 Colaboración de los estudiantes & & \\
\hline & 3.4 Aprendizaje autodirigido & & \\
\hline 1.4 Práctica reflexiva & $\begin{array}{l}\text { 4. Evaluación digital } \\
\text { Usar herramientas digitales para mejorar e innovar }\end{array}$ & & \multirow[t]{2}{*}{ 6.4. Bienestar } \\
\hline \multirow{3}{*}{$\begin{array}{l}\text { 1.5 Desarrollo } \\
\text { Profesional Continuo } \\
\text { Digital (CPD) }\end{array}$} & 4.1 Formatos de evaluación & \multirow{3}{*}{$\begin{array}{l}5.3 \text { Participación } \\
\text { activa }\end{array}$} & \\
\hline & 4.2 Analizar pruebas & & \multirow{2}{*}{$\begin{array}{l}6.5 \text { Solución digital de } \\
\text { problemas }\end{array}$} \\
\hline & 4.3 Retroalimentación y planificación & & \\
\hline
\end{tabular}

Fuente: Pro futuro, a partir de DigCompEdu, The European Commission's science and knowledge service.

\subsubsection{Brindar apoyo socioemocional a los educadores para reducir el estrés y} desgaste emocional

Uno de los efectos colaterales de la pandemia ha sido el aumento del estrés y desgaste profesional de los docentes, confirmado por varias investigaciones en diversos países. En España la Central Sindical Independiente y de Funcionarios (CSIF) de España realizó una encuesta en mayo de 2020 entre una muestra de 612 docentes de Madrid, estableciendo que un 93.6\% de los docentes sufrían desgaste emocional, estrés, angustia o ansiedad durante su trabajo en confinamiento (Gámez, 2020), y este desgaste emocional se acentuaba más en docentes mayores con amplia experiencia en la modalidad presencial y poca habilidad tecnológica. El Centro de Inteligencia Emocional de Yale, junto con la organización CASEL (Collaborative for Academic, Social, and Emotional Learning) encuestó a una muestra de más de 5,000 maestros estadounidenses, estableciendo que las tres emociones experimentadas muy fuertes por los docentes en ese período eran la ansiedad, el temor y la preocupación.

La Fundación Chile y Circular HR realizaron entre el 22 de abril y el 5 de julio de 2020 un estudio sobre el engagement y agotamiento entre 2,657 docentes chilenos de primaria y secundaria (Fundación Chile-Circular HR, 2020). El estudio estableció que al comparar el nivel de agotamiento laboral de docentes con los de otras profesiones, tanto durante 
como previo a la pandemia, el resultado resulta alarmante, porque en otras profesiones el $28 \%$ manifiesta nivel muy alto de agotamiento en tiempo de pandemia, en tanto un $57 \%$ de docentes manifiestan muy alto nivel de agotamiento. Estos datos sugieren, que, si bien distintos tipos de profesionales han debido hacer esta adaptación al contexto de pandemia, pareciera que el efecto ha resultado ser más profundo para el grupo docente, probablemente por las dificultades y mayores exigencias de la adaptación forzada a una modalidad de enseñanza online, y porque la profesión docente ya mostraba alto nivel de agotamiento laboral incluso previo a la llegada de la pandemia.

Adicionalmente, este estudio identificó que el género femenino manifiesta un mayor nivel de agotamiento que el género masculino, más acentuado si existen niñas o niños en su hogar. Durante la pandemia del Ébola de 2014, según el estudio de la Fundación Malala (Malala Fund, 2020), en los países afectados las profesoras afrontaron doble carga de gestionar su trabajo, por el impacto personal de la enfermedad y el cuidado de niños y familiares enfermos, lo que aumentó el abandono de madres de la profesión docente.

En Argentina, la Fundación Vivir en alianza con el Laboratorio de Neurociencias Cognitivas y un conjunto de organizaciones y universidades desarrollaron un estudio exploratorio (Elena et al., 2020) con docentes de distintos niveles educativos (inicial, primario, secundario y superior) con el objetivo de indagar los retos pedagógicos y emocionales que debieron enfrentar durante el período de confinamiento y educación a distancia derivado del COVID-19. Se aplicó a los docentes varios instrumentos como el CERQ (cuestionario de Regulación Emocional Cognitiva), PTGI (inventario de crecimiento post traumático) y el CSC (cuestionario de autocompasión). El estudio concluyó que la mayoría de la población docente tiene necesidad de atender y fortalecer sus recursos emocionales, porque un $70 \%$ se encuentra por debajo de la media en un recurso como la aceptación (reconocer la realidad, con una actitud de apertura a la experiencia sin pretender modificarla) que es clave en la regulación de las emociones; el $50 \%$ no tienen desarrollada la habilidad de perspectiva (dejar de lado la seriedad de una situación o enfatizar la relatividad cuando se compara con otros eventos) o la focalización positiva (pensar en temas o experiencias agradables, en vez de pensar en el suceso real); y el autoculparse alcanza $24 \%$ y $21 \%$ la rumiación (pensar de manera excesiva sobre los sentimientos y problemas asociados a un acontecimiento negativo o desagradable).

En la mayoría de estos y otros estudios los educadores referían como causantes de este desgaste emocional la incertidumbre sobre la situación sanitaria; no distinguir entre horario laboral y personal; aumento de la carga de preparación y adaptación de materiales para educación a distancia; atender la sobrecarga de mensajes recibidos de autoridades del centro educativo, 
estudiantes y padres; limitaciones en el uso óptimo de las nuevas tecnologías; falta de coordinación entre colegas docentes, carga burocrática y a veces innecesaria solicitada por el centro educativo; y la sensación que las autoridades educativas no los toman en cuenta en las decisiones.

Atender esto es importante, porque las políticas y acciones educativas para encarar la educación remota en tiempos de pandemia han priorizado los factores externos y condicionantes del proceso de enseñanza (recursos, competencias tecnológicas, entre otros), pero poco se trabaja sobre la dimensión personal y el fortalecimiento de recursos emocionales en los educadores para enfrentar esta crisis, que puede afectar el mismo proceso de aprendizaje.

Para orientar la planificación de este tipo de apoyo pueden verse como ejemplos el Decálogo propuesto por la Asociación Nacional de Profesionales de la Enseñanza de España (ANPE), las Recomendaciones de apoyo emocional para docentes elaborado por Jara (2020) de la Universidad Autónoma de Chile, documentos de Ministerios y Secretarías de educación como las «4 claves del autocuidado docente» del Ministerio de Educación de Chile (2020), el material de difusión sobre soporte socioemocional a docentes elaborado por el Ministerio de Educación de Perú (2020), entre otros. Estos documentos enfatizan fortalecer el autocuidado docente, buscar medios y espacios para recuperar energía y bienestar, conducir positivamente los pensamientos y cuidar las relaciones, entre otros.

\subsubsection{Favorecer la planificación en un trabajo priorizado, cooperativo y coordinado} entre docentes, para apoyarse mutuamente, no sobrecargar a estudiantes y procurar la mejora continua de la calidad formativa a distancia o híbrida

En esta pandemia promover el trabajo cooperativo y coordinado se ha convertido en un aspecto relevante, para evitar la sobrecarga y no complejizar el trabajo de profesores y estudiantes en un contexto adverso. Por ello, UNICEF Argentina (Castro, 2020), propone a los directivos ir registrando las acciones y prácticas que han llevado adelante en el centro educativo, ir evaluando y ajustando esas acciones con el equipo docente y administrativo, en una cultura de mejora continua de la calidad de la formación a distancia o híbrida.

Reiniciar la educación en modalidad a distancia, se hizo de manera abrupta en varios países, sin la preparación adecuada de los docentes, sin contar con recursos educativos y formación en evaluación de aprendizajes para esta modalidad, entre otros factores. El siguiente reto es que esa educación virtual, a distancia o híbrida, mejore en su calidad, logre los objetivos de aprendizaje en cada grado y nivel educativo, y mantener la motivación de los estudiantes. 


\section{CUADRO 5. RECOMENDACIONES PARA EL BIENESTAR EMOCIONAL DOCENTE FRENTE A LA CRISIS DEL COVID-19}

1. Reconozca las emociones que siente y valídelas. Toda emoción es importante.

2. Si en algún momento siente que alguna emoción es muy intensa, busque actividades que funcionen para usted: intente hacer ejercicios de respiración, jugar con su mascota, escuchar música, pararse unos minutos bajo el sol, pintar, bailar, etc. Calmar la mente es un primer paso para retomar las actividades cotidianas y académicas.

3. Es comprensible si está teniendo problemas para concentrarse en las actividades laborales. Tenga en cuenta que es normal que los niveles de atención, concentración y productividad disminuyan durante épocas de crisis.

4. Genere rutinas y horarios específicos para las actividades de su casa y del IESP (instituciones de educación superior pedagógica). Considere metas cortas que pueda alcanzar. Esto la/lo ayudará a organizarse y disminuir la incertidumbre.

5. Distribuya las actividades de la casa en familia. Elabore un horario para organizar las actividades en las que también se considere un tiempo de descanso para uno mismo que se respetado por los demás miembros de la familia.

6. Genere espacios de diálogo con sus familiares y amigos. Compartir sentimientos ayuda a aliviar el estrés.

7. Evite la sobreexposición a las noticias sobre la pandemia para prevenir el estrés y ansiedad.

8. Recurra siempre a fuentes oficiales que brinden información fiable sobre el COVID-19.

9. Solicite apoyo profesional si siente que sus emociones son muy intensas y están presentes por un período largo de tiempo.

Fuente: Ministerio de Educación de Perú.

UNICEF (2020 a) estima que a nivel mundial uno de cada tres niños aún no recibe una educación a distancia de calidad, y considera que la interrupción prolongada de los servicios de educación preescolar y de primera infancia, afectará más a los niños y niñas más pequeños que requieren alto grado de interacción humana, y la educación a distancia han demostrado ser menos efectiva en esos niveles. 
Según un estudio del Banco Mundial, citado por Ola (2021), como consecuencia del cierre de escuelas y el riego de abandono escolar, la desmotivación por un inadecuado aprendizaje a distancia, la reducción del tiempo efectivo de clases, entre otros factores, Guatemala podría perder 1.5 años de escolaridad promedio, pasando de 6.3 a 4.8, y podrían bajar los niveles de aprendizaje en habilidades lectura, matemáticas y ciencias que suelen medirse a través de pruebas estandarizadas internacionales, y afectar el inicio del grado y nivel educativo siguiente. Esto debe obligar a tomar medidas para priorizar contenidos y áreas curriculares, mejorar la metodología y sistema de evaluación en educación a distancia o híbrida, lo que incluye un urgente fortalecimiento de los educadores para esta modalidad de estudio en tanto las escuelas sigan cerradas.

En este sentido, los educadores deben atender aspectos fundamentales que el Dr. Pedro Morales S.J., académico de la Universidad Pontificia de Comillas y profesor visitante de la Universidad Rafael Landívar de Guatemala, resumió magistralmente en su clásico texto "El profesor educador» (Morales, 2010) y otros:

a) El centro del aprendizaje sigue siendo el alumno a quien estamos llamados a acompañar para que siga aprendiendo en condiciones adversas, a distancia o en modalidad híbrida, y a quien en esta crisis -más que nuncadebemos escuchar, cuidar y proteger. En este sentido es importante recordar que el aprendizaje, aún en la virtualidad es un proceso cognitivo y emocional:

Sabemos de sobra que el aprender no es un proceso meramente cognitivo o intelectual; en buena medida es también un proceso emocional, y si nos tomamos en serio esta dimensión emocional (simplemente procurando que los alumnos se sientan bien para que aprendan más y mejor) tendremos que cuidar nuestra relación con los alumnos, y ya estamos integrando docencia y educación en una única función (...) No confundamos lo que solemos llamar relaciones humanas con la buena relación a la que me refiero ahora, que se da en la clase y en un contexto docente y de aprendizaje. Si los alumnos no aprenden, si el profesor no enseña bien, ahí no hay una buena relación en el aula, porque a clase se va, en primer lugar, a enseñar y a aprender, no a pasarlo bien (y mucho menos a pasarlo mal). (Morales, 2010, pp. 3-4)

b) En esta adversidad y esta modalidad de educación a distancia el estudiante también puede tener aprendizajes no pretendidos, que pueden ser positivos o negativos. En el actual contexto formativo en pandemia, se puede enseñar a gustar o a odiar la educación a distancia o híbrida.

La única consecuencia de la enseñanza no es el aprendizaje logrado por los alumnos y que demuestran después en un examen; también podemos conseguir que nuestros alumnos terminen hartos y no quieran aprender más, al menos no 
más de nuestra asignatura. Pensamos en lo que queremos conseguir (que nuestros alumnos aprendan), pero ¿pensamos alguna en lo que conseguimos sin pretenderlo? (...) La autoeficacia o el sentirse capaz es una actitud aprendida, la enseña el profesor con su modo de relacionarse con los alumnos, con su estilo docente y con cómo maneja todo el tema de la evaluación. (Morales, 2010, pp. 5-7)

c) En el contexto a distancia o híbrida, hay que preservar el diálogo en clases sincrónicas, más allá de los contenidos propios de la asignatura y que retroalimenten el sentir de los estudiantes sobre el proceso formativo:

Podemos ampliar el diálogo con la clase haciendo ocasionalmente preguntas por escrito. No me refiero a preguntas de conocimientos, evaluaciones convencionales, etc., sino a preguntas que de una manera $u$ otra tengan que ver con su cómo se sienten en clase con nosotros. Podemos establecer una relación por correspondencia, un tanto inusual pero que... puede que no sea una mala idea. Podemos preparar cuestionarios muy breves (que pueden ser también preguntas añadidas a evaluaciones y exámenes) en los que podemos preguntar a nuestros alumnos: Qué piensan sobre la dificultad de lo que se va viendo, o sobre el ritmo de la clase, o sobre cualquier otra cosa relevante en un momento dado. (Morales, 2010, p. 35)

El ministerio de Educación de Chile también establece unas recomendaciones para el adecuado acompañamiento de los alumnos por parte de los educadores, entre las que puede destacarse:

- Considere que muchos de sus estudiantes pueden percibir esta situación como la pérdida de momentos cotidianos que incluían conversar con sus amigos y participar en clase, lo que puede generar un impacto a nivel emocional.

- Busque espacios en los que expresen y comuniquen sus sentimientos, porque las palabras son importantes, al igual que la identificación y validación de las emociones.

- Asegúrese de escuchar las inquietudes de sus estudiantes y de responder las preguntas que pueda, y tenga en cuenta que es válido reconocer y comunicar a los estudiantes cuando no se tiene la respuesta idónea en ese momento.

- Invite a que elaboren un horario con sus actividades académicas e incluyan espacios de descanso, metas cortas y realistas que pueden alcanzar.

- Si identifica inasistencia recurrente de uno o más de sus estudiantes, se sugiere llamarle o escribirles para conocer el motivo por el que no participa de las clases. 
- Si identifica que algún estudiante necesita ayuda psicológica profesional, sugiérales comunicarse con las líneas de apoyo adecuadas (Ministerio de Educación de Perú, 2020).

d) La forma de evaluar puede condicionar el éxito o fracaso de los estudiantes, y «la manera más rápida y eficaz de cambiar y mejorar el cómo estudian los alumnos consiste en cambiar el modo de evaluación», porque la evaluación "es una oportunidad para algo más», es un «método eficaz de informar al alumno a tiempo para evitar el fracaso» y es un «método eficaz para condicionar el cómo estudia el alumno»(Morales, 2010, p. 41). Algo importante, porque en este proceso de migración a una educación a distancia o híbrida pusimos el foco en los medios y en el método de enseñanza, y menos en la evaluación en modalidad a distancia que sigue siendo la asignatura pendiente en esta crisis.

Si realmente queremos, con voluntad eficaz, que todos los alumnos sepan o comprendan algo especialmente importante, la solución no es complicada: preguntémoslo antes del examen. No vamos a preguntar todo, pero sí podemos hacer preguntas-clave. Aprendemos, los alumnos y también nosotros, cuando sabemos en qué y por qué nos hemos equivocado. Y naturalmente, si hemos tenido la oportunidad de equivocarnos... sin esperar a un examen. Como no podemos estar examinando todos los días, ni fuera de las fechas señaladas, habrá que pensar en otras formas de evaluación más sencillas, que no supongan mucho trabajo extra, pero con una finalidad muy definida: informar a tiempo. Incluso las preguntas orales pueden servir, pero solamente si tenemos claro qué pretendemos con esas preguntas y los alumnos lo saben. También tiene que estar claro que el objetivo no es calificar. (Morales, 2010, p. 40)

En este sentido Pedro Morales, en otros de sus textos ofrece importantes orientaciones para evaluar y que se hacen más pertinentes y necesarios en contextos de pandemia o emergencias. Así, propone diseñar trabajos breves para hacer en casa (Morales, 2011, pp. 3-4) porque "por su brevedad y estructura simple se pueden corregir y calificar fácilmente y con rapidez», y la brevedad no necesariamente está reñida con la calidad y obliga al alumno a ser más preciso; «admiten una mayor frecuencia sin que esto suponga necesariamente una carga excesiva para profesores y alumnos»; "no se prestan fácilmente a ser copiados de otras fuentes pues en ningún caso se trata de exponer un tema», entre otras bondades. Entre estas estrategias destaca el denominado «One minute paper», que supone pedir a los alumnos al final de la clase que respondan por escrito y en forma breve dos preguntas: a) ¿Qué ha sido para ti lo más importante que has aprendido en esta clase?, y b) ¿Qué es lo que te ha quedado más confuso?, o preguntas similares, obteniendo el profesor un feedback inmediato sobre cómo los alumnos van comprendiendo 
la clase y responder o profundizar las dudas al inicio de la siguiente clase (Morales, 2011b, pp. 2-3).

e) Aprovechar esta crisis para motivar la innovación pedagógica. Como señala UNESCO en su campaña denominada «La nueva normalidad», el COVID-19 ha puesto en tela de juicio nuestras prioridades, nuestros modos de vida, el funcionamiento de nuestras sociedades, y la educación no es la excepción. Esta es una oportunidad privilegiada para construir algo mejor que lo normal, y que no debe desaprovecharse. En este sentido diversos académicos han planteado que estamos ante la oportunidad de un renacimiento de la educación postpandemia (Reimers, 2020), que responda de manera creativa e innovadora a los aprendizajes y retos que ha planteado esta pandemia en cada contexto, enriqueciendo lo presencial con lo mejor de la virtualidad, preservando -como señala el profesor Pedro Morales- el rol del docente como educador, y mantener la enseñanza centrada en el aprendizaje y la autoapertura docente en el contexto de los determinantes del aprendizaje escolar (Torre, 2004).

La educación postpandemia, en su finalidad, currículo y métodos, no puede ser la misma que se ofrecía antes de la pandemia. Ahora, más que nunca, se hace necesario formar para la conciencia de interdependencia plantearía, la identidad terrenal y el desarrollo sostenible; recuperar la formación de personas virtuosas, libres y plenas, pero éticas, compasivas y sensibles a la condición humana; formar personas capaces de enfrentar las incertidumbres (cfr. Objetivos de desarrollo sostenible de UNESCO; Morin, 1999; Savater, 1997, entre otros); y formar mentes innovadoras que ayuden a resolver en equipos multidisciplinares los grandes males de la humanidad, con capacidad de «anticiparse con criterio lúcido, crítico y fundamentado a lo que el presente augura que podrá suceder en el futuro»(Rodríguez, 2020).

\subsection{COOPERACIÓN ENTRE MAESTROS Y PADRES DE FAMILIA}

Con la pandemia y la suspensión de actividades educativas presenciales, la educación que se ofrecía en los centros educativos con baja participación de padres de familia, se traslada al ámbito privado de los hogares y requiere una mayor participación de los familiares, especialmente las madres de familia con niños y niñas de niveles educativos infantiles y para lo que no estaban preparados. Esta presión por la supervisión y apoyo educativo y emocional de los hijos en casa, se agudizó por la presión laboral y sanitaria, y en algunos casos críticos afectó las relaciones humanas en el hogar. 


\subsubsection{Apoyar el cuidado integral y socioemocional de niñas, niños y jóvenes} en casa

Durante la crisis de pandemia del Ébola, los niños y especialmente las niñas vieron aumentar los efectos de la violencia familiar, efectos psicoemocionales por pérdidas familiares afectando su aprendizaje (Malala Fund, 2020), en otros casos el miedo al retorno alejó a niños de la escuela,

El abuso infantil en el hogar: Para niños y niñas que viven violencia o abusos en su hogar y contexto social, la escuela se vuelve un entorno protector. Pero algo lamentable en el período de confinamiento en esta pandemia de Ébola, fue que las niñas al estar en casa tuvieron mayor riesgo de explotación y abuso sexual. La tasa general de embarazos en adolescentes se duplicó, y se ha calculado que las niñas de 12 a 17 años tenían $7.2 \%$ más probabilidad de quedar embarazadas durante el confinamiento. Durante la pandemia de Covid-19, parece repetirse este patrón en algunos países. En Guatemala, en la Ciudad de Quetzaltenango que es la segunda ciudad más importante del país, aumentaron las denuncias por abuso infantil a pocos meses de iniciado el confinamiento. Según datos del Ministerio Público en el primer semestre de 2020 se habían presentado en esa ciudad 176 denuncias de abuso infantil (Juárez, 2020), y este dato no refleja los casos que no son denunciados por temor. Si esto sucede en una ciudad, puede inferirse el número total de casos en todo el país.

La Comisión económica para América Latina y El Caribe (CEPAL) y UNICEF, publicaron en diciembre de 2020 un amplio estudio denominado «Violencia contra niñas, niños y adolescentes en tiempos de COVID-19» (CEPAL-UNICEF 2020), que alerta de la disminución de los factores de protección ante la violencia física, psicológica y sexual a la que se exponen en su hogar y en el entorno virtual (ciber acoso) los adolescentes, niños y especialmente las niñas durante la pandemia de COVID-19. El documento ofrece algunas recomendaciones para enfrentar este problema silencioso, aún no dimensionado totalmente.

En esta línea, representantes de más de 22 importantes organismos y entidades internacionales (OMS, UNICEF, ONU mujeres, World Vision, Save the Children International, ChildFund Alliance, World Vision International, Plan Internacional y otros) suscribieron una declaración denominada «Violencia contra los niños: Una crisis oculta vinculada a la pandemia por COVID-19», exhortando a los gobiernos a «velar por que los planes de prevención y respuesta en torno a la COVID-19 incluyan medidas adecuadas a cada edad y sensibles a las necesidades de los géneros, para proteger a todos los niños frente a la violencia, el abandono y el maltrato", y solicitan que los servicios 
de protección de la infancia y trabajadores que prestan esos servicios sean considerados como esenciales.

Brindar apoyo socioemocional a los alumnos. Los niños que habían presenciado enfermedad y muerte de familiares en la crisis del Ébola, sufrieron problemas de salud mental, una situación grave si se considera que unos 16.000 niños perdieron a uno o ambos padres (Malala Fund, 2020). Los estudiantes también han sido afectados socioemocionalmente por la pandemia COVID-19, porque les genera sentimientos de miedo, incertidumbre, enojo, pérdida y tristeza por fallecimiento de familiares, o porque se desgastan las relaciones sociales familiares. Por estas razones los gobiernos con apoyo de importantes organismos y cooperantes internacionales vienen desarrollando e implementando programas de aprendizaje socioemocional para ayudar a los estudiantes a aprender las competencias y habilidades que necesitan para desarrollar la resiliencia, manejar eficazmente sus emociones y comportamiento social; formar a docentes y familiares para coadyuvar al bienestar psicosocial de los estudiantes; fortalecer la capacidad de las instituciones educativas para promover espacios virtuales y físicos de aprendizaje protegidos, y apoyar a niños, niñas y jóvenes que están viviendo dificultades psicosociales o de salud mental.

Entenderemos el aprendizaje socioemocional como el proceso mediante el cual los niños y adultos adquieren y desarrollan conocimientos, habilidades y actitudes que les permiten lograr el autoconocimiento, comprender y autorregular las emociones y su expresión, motivarse para establecer y alcanzar objetivos positivos, empatizar con los demás, construir y mantener relaciones positivas, tomar responsablemente sus decisiones y manejar de manera efectiva situaciones desafiantes. (Goleman, 1996; Bisquerra, 2000; CASEL, 2019, citados por Ministerio de Educación de Chile-DEG, 2020, p. 4)

Existe abundante reflexión y orientaciones al respecto, baste citar como ejemplos la fundamentación para el plan de trabajo y recursos sobre aprendizaje socioemocional elaborado por el Ministerio de Educación de Chile (Ministerio de Educación de Chile-DEG, 2020); el Kit de Apoyo Socioemocional para abordar efectos de la pandemia en escolares elaborado por el Ministerio de Educación de Colombia y UNICEF; o el relevante seminario internacional virtual «Salud mental, apoyo psicosocial y aprendizaje socioemocional: acciones comunes ante el COVID-19», promovido desde Venezuela con importantes especialistas (Ministerio del poder popular para la educación de Venezuela, 2020).

En esta bibliografía revisada se plantea que los programas de formación socioemocional deben permear la cultura institucional o el clima escolar, y enseñar de manera explícita las habilidades socioemocionales, tanto en 
alumnos, docentes y familiares. La Especialista Regional para la Protección de la niñez de UNICEF, Ana Fernández (2020), plantea un modelo socio ecológico de intervención con 9 acciones que pueden verse en el Cuadro 6.

CUAdRo 6. Modelo ECOLÓGICO PARA ATENDER LA SALUd MENTAL Y APOYO PSICOSOCIAL

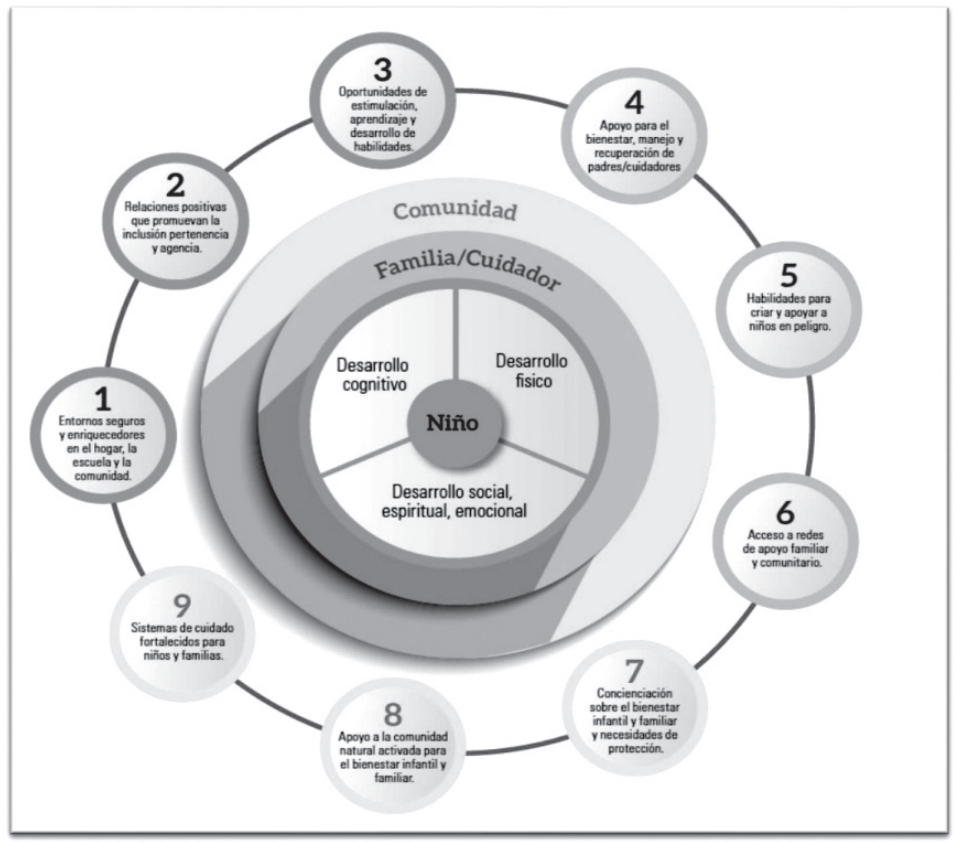

Fuente: Fernández, A. (2020).

El rol de la familia es importante, porque en esta emergencia se trasladó el quehacer estudiantil del centro educativo al ámbito privado del hogar, y eso exige desde el centro educativo cuidar el bienestar socioemocional de los miembros de la familia, y formarlos para cuidar y dar ejemplos de autocuidado a los estudiantes. Con este fin, UNICEF se unió a la iniciativa Parenting for Lifelong Health, formada por organizaciones especializadas en el cuidado de la infancia, para elaborar y ofrecer a las familias o cuidadores una serie de Guías con orientaciones para ayudar a manejar esta situación en las que las familias pueden verse sobrepasadas: parentalidad positiva y enfrentar situaciones difíciles como enfados, seguridad on-line, control del estrés, problemas de comportamiento, convivencia en casas 
pequeñas llenas de gente, entre otras (cfr. UNICEF-Parenting for Lifelong Health, 2020).

Aún después de la pandemia, el desarrollo de un programa integral de aprendizaje socioemocional debe ser algo permanente en los centros educativos, porque diversas investigaciones han demostrado que tiene efectos profundos en el desarrollo y conducta de los estudiantes y en la mejora significativa de los resultados académicos de los estudiantes (Milicic, Alcalay, Berger y Torretti, 2014; Milicic y Aron 2017; Taylor et al. 2017, citados por Ministerio de Educación de Chile-DEG, 2020), además de preparar de mejor manera ante futuras situaciones de emergencia.

\subsubsection{Formar a padres de familia para acompañar proceso de educación a} distancia y cuidado preventivo de la salud y nutrición

Los padres de familia o familiares cercanos también deben ser apoyados y formados para cooperar con los docentes en el estudio de los alumnos desde el hogar, velar por la adecuada alimentación y cuidados de salud en las familias ${ }^{2}$, una necesidad aún más relevante para familiares en contexto de pobreza, con madres que tienen bajo grado de escolaridad y que acompañan a varias niñas y niños la mayor parte del tiempo en el hogar. No es el objetivo de este artículo desarrollar estas orientaciones, pero sí queremos plantear la necesidad de recuperar esa iniciativa de crear un sistema permanente de escuelas de padres o familiares de estudiantes.

\subsection{Subsidio SOlidARIO DE AUTORIDAdES GUbERnAMENTALES A FAMILIAS MÁS POBRES}

Los gobiernos de cada país, además de asegurar la continuidad del proceso formativo, deben apoyar de manear subsidiaria a las familias más afectadas por la pandemia y que corren el riesgo de retirar a sus hijas e hijos de los centros educativos.

\footnotetext{
2 En el tema de la educación de la salud en el contexto escolar pueden verse importantes estudios y propuestas, destacando el libro Promoción de la salud en la escuela; mirada al ayer y retos en América Latina, que sintetiza los hallazgos en la literatura gris y científica de las tendencias teóricas y prácticas de la promoción de la salud en el ámbito escolar, periodo 2007-2017 (Universidad Industrial de SantanderFacultad de Salud, 2020); y las orientaciones de la Organización Mundial de la Salud (OMS) en conjunto con UNESCO y UNICEF (2020), entre otras.
} 
2.4.1. Subsidiar a familias pobres y desempleadas para dotarles de recursos para asegurar continuidad formativa de sus hijas e hijos

El confinamiento y cierre de varias actividades económicas durante la pandemia provocó cierre de empresas, con su secuela de contracción económica, aumento del desempleo o disminución de ingresos económicos en las familias, además de agudizar la pobreza extrema en países en desarrollo como Guatemala. Guatemala tiene la tasa más alta de desnutrición crónica en Latinoamérica, con una desnutrición crónica infantil (y retraso en el crecimiento) que para 2019 afectaba al $47 \%$ de todos los niños menores de cinco años (Banco Mundial, 2020), y según proyecciones de La Comisión Económica para América Latina y el Caribe (CEPAL) y la Organización de las Naciones Unidas para la Agricultura y la Alimentación (FAO) la pandemia de COVID-19 podría aumentar la pobreza extrema en Guatemala del 19.8 al 21.4 por ciento (Morales, 2020).

Como producto de este deterioro en la economía familiar, el riesgo del abandono escolar es alto, al no poder costear la continuidad de la formación, la necesidad de poner a trabajar a hijos e hijas para generar ingresos, o verse forzados a migrar para mejorar sus condiciones de vida. Por ello las autoridades gubernamentales deben apoyar subsidiariamente a las familias más necesitadas, con acciones que incluyan el mantenimiento de los programas de alimentación escolar entregados en casa, garantizar el acceso gratuito a conectividad en hogares pobres, entre otras acciones.

\subsubsection{Implementar programas de apoyo que reduzcan el abandono escolar}

El gran desafío de los sistemas educativos de los países en desarrollo en esta pandemia es la deserción escolar. Durante la crisis de pandemia del Ébola aumentó la deserción de las escuelas por razones económicas (Malala Fund, 2020), muchas familias sufrieron disminución de sus ingresos debido a crisis económica asociada al brote, y las familias más pobres necesitaron a niños y jóvenes para contribuir económicamente en los ingresos familiares. En Sierra Leona el $19 \%$ de niñas entre 12 y 17 años comenzaron a trabajar, y la mayoría de ellas nunca regresó a la escuela al terminar la crisis, porque los estudios pierden prioridad frente a la ayuda económica que su trabajo ofrece a familia. Frente a mayor pobreza y la mortalidad parental, las niñas asumieron más responsabilidades domésticas.

En Guatemala, uno de los niveles más afectados por la pandemia fue la preprimaria, por la dificultad de niñas y niños pequeños de seguir estudios 
a distancia, y no ser vinculante u obligatorio para ingresar a primaria ${ }^{3}$. Esto afectará a niños y niños, por ser una etapa vital que ayuda a preparar el ingreso a la primaria.

En todo el sistema educativo de Guatemala, se estimó en 2019 una deserción total de $7 \%$, y derivado de la pandemia se prevé un aumento de la deserción escolar. Según datos preliminares del Ministerio de educación, en 2020 desertaron 63 mil 855 estudiantes. Por ello es urgente implementar sistemas de alerta de deserción temprana de estudiantes, y programas e incentivos para reducir la deserción escolar que permitan apoyar oportunamente a los estudiantes en riesgo de abandono escolar. Organismos internacionales han planteado que en las estrategias de retorno a las clases después de la pandemia, será fundamental animar a los estudiantes a volver a los centros educativos y recuperar de manera remedial los aprendizajes débiles o perdidos.

\section{CONCLUSIONES}

Este marco orientador, que puede ser enriquecido, quiere ser un aporte hacia el diseño de la educación postpandemia. Como decía el Papa Francisco en la vigilia de Pentecostés de 2020, «cuando salgamos de esta pandemia, no podremos seguir haciendo lo que veníamos haciendo, y cómo lo veníamos haciendo (...) de las grandes pruebas de la humanidad, y entre ellas de la pandemia, se sale o mejor o peor», de nosotros depende cómo queremos salir. El mismo Papa Francisco ha convocado a un Pacto Educativo Global, con la convicción de que en la educación se encuentra la semilla de la esperanza para construir nuevos paradigmas capaces de responder a los desafíos y emergencias del mundo contemporáneo, y para hacer que la humanidad florezca (Lobos, 2020).

\footnotetext{
3 Según datos de la Asociación de Colegios Privados de Guatemala, se estima que la deserción escolar en preprimaria alcanzó el $40 \%$ en los colegios privados agremiados a esa asociación, unos 38 mil 235 niñas y niños (Ola, 2020), de un total de 596 mil 318 niños estudiando este nivel a nivel nacional.
} 


\section{REFERENCIAS}

Banco Mundial (2020). Guatemala Panorama General, en página web del Banco Mundial en Guatemala, actualizado al 9 de octubre de 2020. Recuperado de https://www.bancomundial.org/es/country/guatemala/overview

Castro, C. (2020). Acompañar la tarea del equipo docente, las familias y estudiantes en casa. Buenos Aires: Fondo de las Naciones Unidas para la Infancia. Recuperado de https://www.unicef.org/argentina/media/8431/file

CEPAL-UNICEF (2020). Violencia contra niñas, niños y adolescentes en tiempos de COVID-19. Naciones Unidas: CEPAL-UNICEF. Recuperado de https://www.cepal. org/sites/default/files/publication/files/46485/S2000611_es.pdf

CEPAL y UNESCO. (2020). La educación en tiempos de la pandemia de COVID-19. Recuperado de https://www.cepal.org/es/publicaciones/45904-la-educacion-tiempos-la-pandemia-covid-19

Díaz Arce, D. y Loyola, E. (2021). Competencias digitales en el contexto COVID 19: una mirada desde la educación. Revista Innova educación, Vol. 3, Núm. 1, enero 2021. Recuperado de http://revistainnovaeducacion.com/index.php/rie/article/ view/181/212

Duro, E., Bonelli, S., Cortes, R., Cortelezzi, M. y Llobenes, L. (2020). Recursos emocionales en la población en contexto COVID-19. Una exploración en la población docente. Buenos Aires: Fundación Vivir. Recuperado de https://unso.edu.ar/Informe-Bienestar-Emocional-en-contexto-de-COVID-19-Observatorio.pdf

Fernández, A. (2020). Debemos pasar de intervenciones enfocadas solo en el estudiante hacia acciones integrales que vean que ese niño o niña es parte de una familia, una comunidad y una sociedad. Ponencia en Ministerio del poder popular para la educación de Venezuela-Cluster de educación (2020) Salud mental, apoyo psicosocial y aprendizaje socioemocional: acciones comunes ante el COVID-19. Venezuela: Ministerio del poder popular para la educación. Recuperado de https:// reliefweb.int/sites/reliefweb.int/files/resources/seminario_salud_mental_apoyo_ psicosocial_y_aprendizaje_socioemocional_cluster_educacion_ven.pdf

Fundación Chile-Circular HR (2020). Engagement y agotamiento en las y los docentes de Chile. Una mirada a partir de la realidad COVID-19. Santiago de Chile: Fundación Chile. Agosto 2020. Recuperado de https://fch.cl/wp-content/uploads/2020/09/ final-estudio-engagement-docentes.pdf

Gámez, B. (2020). El 93.6\% de los docentes sufre estrés y desgaste emocional debido al confinamiento. Magisterio, 2 de junio de 2020. Recuperado de https://www. magisnet.com/2020/06/el-936-de-los-docentes-sufre-estres-y-desgaste-emocionaldebido-al-confinamiento/

Grupo Banco Mundial (2020). Cerrar la brecha digital. Conversatorio en el marco de las Reuniones anuales del Grupo Banco Mundial, realizadas del 12 al 18 de octubre de 2020. Recuperado de https://www.youtube.com/watch?v=USCMGYJiylY\&t=382s

INFOBAE (2018). Bill Gates llama a EEUU a liderar la lucha contra una pandemia que podría matar a 33 millones de personas. INFOBAE, versión digital del 4 de mayo de 2018, recuperado de https://www.infobae.com/america/wapo/2018/05/04/billgates-llama-a-eeuu-a-liderar-la-lucha-contra-una-pandemia-que-podria-matar-a33-millones-de-personas/ 
INFOBAE (2020). De la peste negra al coronavirus: cuáles fueron las pandemias más letales de la historia. INFOBAE, versión digital del 18 de marzo de 2020. Recuperado de https://www.infobae.com/america/mundo/2020/03/18/de-la-peste-negraal-coronavirus-cuales-fueron-las-pandemias-mas-letales-de-la-historia/

Informe GEM (2020). Coronavirus: ¿los sistemas educativos podrían haber estado mejor preparados? Blog de la educación disponible, publicado el 19 de marzo de 2020. Recuperado de https://educacionmundialblog.wordpress.com/2020/03/19/ coronavirus-los-sistemas-educativos-podrian-haber-estado-mejor-preparados/

Instituto Nacional de Estadística (2018). Censo de población y Vivienda 2018. Guatemala: INE.

Jara, L. (2020). Recomendaciones de apoyo emocional para docentes. Chile: Universidad Autónoma de Chile - Escuela Padre Bartolomé de las Casas. Recuperado de https://es.calameo.com/read/006273838f659d7c80828

Juárez, R. (2020). Aumentan en Xela las denuncias por abuso infantil, el confinamiento sería una de las principales causas. El Quetzalteco, 22 de julio de 2020.

Lobos, S. (2020). El Papa pide unirse al Pacto Educativo Global. VATICAN NEWS, versión digital del 15 de octubre de 2020.

Malala Fund (2020). Girls' Education and Covid-19. What past shocks can teach us about mitigating the impact of pandemics. Recuperado de https://downloads.ctfassets.net/0oan5gk9rgbh/6TMYLYAcUpjhQpXLDgmdIa/3e1c12d8d827985ef2b4 e815a3a6da1f/COVID19_GirlsEducation_corrected_071420.pdf

Mantilla, B., Hernández, J., Hakspiel, M. C., Rincón, A. y Oviedo, M. P. (2020). Promoción de la Salud en la Escuela: Mirada al ayer y retos en América Latina. Colombia: Universidad industrial de Santander. Recuperado de http://proinapsa.uis.edu.co/ index.php/top-blocks/233-libro

Ministerio de Educación de Chile-DEG (2020). Aprendizaje socioemocional. Fundamentación para el plan de trabajo. Santiago: Ministerio de Educación de Chile-DEG. Recuperado de http://convivenciaescolar.mineduc.cl/wp-content/ uploads/2020/07/FUNDAMENTACION-PLAN-DE-TRABAJO.pdf

Ministerio de Educación de Perú (2020). Material de difusión sobre soporte socioemocional a docentes del IESP, disponibles en la página web del Ministerio de Educación. Recuperado de http://www.minedu.gob.pe/superiorpedagogica/material-de-difusion-sobre-soporte-socioemocional-a-docentes-de-iesp/

Ministerio del poder popular para la educación de Venezuela-Cluster de educación (2020). Salud mental, apoyo psicosocial y aprendizaje socioemocional: acciones comunes ante el COVID-19. Venezuela: Ministerio del poder popular para la educación. Recuperado de https://reliefweb.int/sites/reliefweb.int/files/resources/ seminario_salud_mental_apoyo_psicosocial_y_aprendizaje_socioemocional_ cluster_educacion_ven.pdf

Montepeque, F. (2021). Mineduc sin datos certeros sobre deserción escolar en 2020. El Periódico, publicado el 26 de enero de 2021 en versión digital. Recuperado el 26 de enero de 2021 de https://elperiodico.com.gt/nacionales/2021/01/26/mineducsin-datos-certeros-sobre-desercion-escolar-en-2020-1/

Morales, P. (2010). El profesor educador. Madrid: Universidad Pontificia Comillas. Recuperado de https://3699dea9-7151-4213-bf21-9ab04a3c21a6.filesusr.com/ ugd/8d49cf_c8d1f542dab34970a3bd0d0a85a9cb16.pdf 
Morales, P. (2011 a). Trabajos breves para hacer en casa. Guatemala: Universidad Rafael Landívar. Recuperado de https://3699dea9-7151-4213-bf21-9ab04a3c21a6. filesusr.com/ugd/8d49cf_628e28863a55427f9cad32321aca043b.pdf

Morales, P. (2011 b). El «one minute paper». Guatemala: Universidad Rafael Landívar. Recuperado de https://3699dea9-7151-4213-bf21-9ab04a3c21a6.filesusr.com/ugd/ 8d49cf_2ecf645570d04334835b5edf40d25753.pdf

Morales, S. (2020). Coronavirus dejará en Guatemala 300 mil pobres extremos más, en PRENSA LIBRE, versión digital del 17 de junio de 2020. Recuperado de https:// www.prensalibre.com/guatemala/comunitario/coronavirus-dejara-en-guatemala300-mil-pobres-extremos-mas/

World Health Organization, UNICEF y Unesco (2020). Considerations for school-related public health measures in the context of COVID-19. Recuperado de https:// unesdoc.unesco.org/ark:/48223/pf0000374258

Ola, A. (2020). Deserción escolar en preprimaria alcanza el $40 \%$ en los colegios, en Prensa Libre, 8 de septiembre de 2020, versión digital.

Pais, A. (2020). Coronavirus: 4 países de América Latina que lograron aplicar estrategias exitosas de educación a distancia ante la pandemia, en $B B C N E W S$, versión digital del 24 de abril de 2020. Recuperado de https://www.bbc.com/mundo/ noticias-america-latina-52375867

RAE, Diccionario de la Real Academia Española de la Lengua.

Redacción BBC News Mundo (2017). «El mundo es vulnerable a una gran epidemia, le dice Bill Gates a la BBC», versión digital del 1 de enero de 2017. Recuperado de https://www.bbc.com/mundo/noticias-38470286

Redacción BBC News Mundo (2020). «Nos enfrentamos a la amenaza muy real de una pandemia fulminante»: la advertencia de la OMS sobre el riesgo de una emergencia sanitaria, en $B B C N E W S$, versión digital del 18 de septiembre 2019. Recuperado de https://www.bbc.com/mundo/noticias-49745206

Rodas, H. (2020). Competencias digitales en el proceso de enseñanza-aprendizaje del docente y estudiante. Revista Guatemalteca de Educación Superior, 3(2), 12-23. Recuperado de https://doi.org/10.46954/revistages.v3i2.28

Rodríguez, J. (2020). Plan para una educación postpandemia, en EA, Asociación educación abierta. Recuperado de https://educacionabierta.org/plan-para-unaeducacion-postpandemia/

Savater, F. (1997). El valor de educar. México: IEESA.

Torre, J. (2004). La autoapertura docente en el contexto de los determinantes del aprendizaje escolar, en Torre, J. C. y Gil, E. (eds.) (2004). Hacia una enseñanza universitaria centrada en el aprendizaje. España: Universidad Pontificia de Comillas, 219-256.

UNESCO, UNICEF, BM, PMA (2020). Marco para la reapertura de las escuelas, abril de 2020. Recuperado de SPANISH-Framework-for-reopening-schools-2020.pdf (unicef.org)

UNICEF (2020). Dos tercios de los niños en edad escolar del mundo no tienen acceso a Internet en el hogar, Comunicado de prensa del 1 de diciembre de 2020. Recuperado de https://www.unicef.org/es/comunicados-prensa/dos-tercios-ninosedad-escolar-mundo-no-tienen-acceso-internet-en-hogar 
UNICEF (2020 a). Informe Educación en pausa. Una generación de niños en América Latina y el Caribe está perdiendo la escolarización debido al COVID-19. Panamá: 2020. Recuperado de https://www.unicef.org/lac/media/18251/file/Educacion-enpausa-web-1107.pdf

UNICEF (2020 b). La falta de igualdad en el acceso a la educación a distancia en el contexto de la COVID-19 podría agravar la crisis mundial del aprendizaje, Comunicado de prensa del 5 de junio de 2020. Recuperado de https://www.unicef.org/es/ comunicados-prensa/falta-igualdad-acceso-educacion-distancia-podria-agravarcrisis-aprendizaje

UNICEF-Parenting for Lifelong Health (2020). La educación en familia en tiempos del COVID-19. Recursos disponibles en https://www.unicef.es/educa/biblioteca/ educacion-familia-covid-19

Universidad Rafael Landívar (2020). Resultados de encuesta a estudiantes realizada del 27 de marzo al 2 de abril. Guatemala: Vicerrectoría Académica-Departamento de Planificación y Seguimiento. 



\section{Notas, TEXTOS Y COMENTARIOS}


